\title{
Outcome comparison between percutaneous cholecystostomy and cholecystectomy: a 10-year population- based analysis
}

Ping Lu ${ }^{1,2+}$, Chien-Lung Chan ${ }^{2,8+}$, Nan-Ping Yang ${ }^{3,4}$, Nien-Tzu Chang ${ }^{5 \dagger}$, Kai-Biao Lin ${ }^{6,7}$ and K. Robert Lai ${ }^{6,8^{*}+}$

\begin{abstract}
Background: Controversy surrounding the role of percutaneous cholecystostomy (PC) is fed by the absence of large amounts of data concerning its outcomes, and many authors have maintained that there is no evidence to support a recommendation for PC rather than cholecystectomy (CCS) in elderly or critically ill patients with acute cholecystitis (AC).
\end{abstract}

Methods: We conducted this study by tracking trends in the utilization and outcomes of PC and CCS using longitudinal health research data in Taiwan.

Results: Analyses were conducted on 236,742 patients, 11,184 of whom had undergone PC and 225,558 of whom had undergone CCS. Average annual percentage changes (AAPCS) from 2003 to 2012 increased significantly by 18. $34 \%$ each year for PC and by $2.82 \%$ each year for CCS. The subset analyzes showed that the mortality rates were far higher in patients underwent PC than in patients underwent CCS in all subgroups, which increased from a minimum of 1.45 -fold to a maximum of 34.22-fold. The gap of the mortality rates between PC group and CCS group narrowed as the patients aged and with the seriousness of the diseases increased. Most patients with PC or CCS who died in-hospital or within 30 days after discharge were 70 years of age or older, and a large number of them received a CCl score of at least 1. The AAPCs of the overall mortality rates from 2003 to 2012 decreased by $6.78 \%$ each year for PC and by 7.33\% each year for CCS. PC was related to a higher rate of cholecystitis recurrence and readmission for complications, but a lower rate of in-hospital complications and routine discharge than CCS, and $36.41 \%$ of all patients treated with PC underwent subsequent CCS. Additionally, the patients with PC experienced longer hospital stays and generated higher costs than the patients with CCS.

Conclusion: Patients who underwent PC demonstrated poorer prognoses than did patients who underwent CCS. The role of PC in the Tokyo guidelines may be overstated; it is not as safe as the Tokyo guidelines have suggested in moderate-grade cholecystitis cases, and it should be limited to only the elderly and sicker patients.

Keywords: Percutaneous cholecystostomy, Cholecystectomy, Acute cholecystitis, Tokyo guidelines

\footnotetext{
* Correspondence: krlai@cs.yzu.edu.tw

${ }^{\dagger}$ Equal contributors

${ }^{6}$ Department of Computer Science and Engineering, Yuan Ze University,

Taoyuan 32003, Taiwan

${ }^{8}$ Innovation Center for Big Data and Digital Convergence, Yuan Ze University,

Taoyuan 32003, Taiwan

Full list of author information is available at the end of the article
} 


\section{Background}

While cholecystectomy (CCS) is the standard treatment for acute cholecystitis (AC) [1, 2], this approach poses significant mortality risks from urgent surgery to elderly and critically ill patients [3]. Percutaneous cholecystostomies (PCs), which involve percutaneous, imagingguided catheter placement in the gallbladder lumen, were first described by Radder in 1980 [4]. This procedure allows for the immediate decompression of an acutely inflamed gallbladder, requires the use of only local anesthesia, thus eliminating the need for surgery, and can serve as either a bridge to surgery or as a definitive treatment designed for unfit patients and for those who refuse to undergo CCS [5-8]. The Tokyo guidelines, first in 2007 and then again in 2013, considered that the use of PC not only as an alternative procedure in critically ill patients but also as a bridge to surgery in patients with moderate-grade cholecystitis $[9,10]$. However, PC has not been proven to be an effective alternative to early surgery. Many authors have maintained that there is no evidence to support a recommendation for $\mathrm{PC}$ other than CCS in elderly or critically ill patients with AC $[11,12]$. Controversy surrounding the role of $\mathrm{PC}$ is fed by the absence of reliable data concerning its outcomes. Some studies have reported that the mortality rate is far higher after PC than after CCS, even for critically ill patients $[13,14]$. Thus, we could not determine whether the Tokyo guideline recommendations were adequate and current or whether they should be revised due to the lack of large amounts of data.

Although previous epidemiological studies have compared the health outcomes of PC and CCS, most of these studies have been based on hospital-level patient data [15]. Huang et al. [16] conducted a populationbased study to assess trends in the incidence of severe gallstone disease in Taiwan among adults aged $\geq 20$ years in 2009, but this study did not refer to PC procedures. To the best of our knowledge, only Anderson et al. [17], in 2013, have conducted a nationwide examination of the outcomes of PC compared to the outcomes of CCS for AC. Therefore, in-depth population-based research and analyses must be conducted to investigate possible roles of $\mathrm{PC}$ in the management of $\mathrm{AC}$ and other gallbladder diseases. These analyses may lead to treatment suggestions for medical research institutions and surgeons when making decisions concerning the management of patients with $\mathrm{AC}$ and the judicious use of $\mathrm{PC}$ and CCS.

\section{Methods}

\section{Study subjects and data source}

Taiwan's National Health Insurance (NHI) program launched in 1995; by 2011, the coverage rate had expanded to $99.9 \%$. All enrollees can access health care services from most hospitals and clinics. The Bureau of NHI established a population-based research database that includes nationwide data that is both high quality and representative. Various data subsets, such as inpatient expenditures, details of prescription orders, and clinic or ambulatory care expenditures, were included in the NHI research database (NHIRD). In this study, the inpatient data and prescription orders by admissions were used for further analysis.

\section{Data protection and permission}

All the subjects' information was double encrypted to protect the patients' privacy. All researchers are required to declare and sign a written agreement before using these data subsets. This study was also approved by the research ethics committee of Taoyuan General Hospital (Approval Number: TYGH103015), which has been certified by the Ministry of Health \& Welfare of Taiwan, and the research protocol was required to be reviewed by the National Health Research Institutes (Agreement Number: NHIRD-104-081).

\section{Data definition}

To compare the trends and outcomes of PC and CCS in Taiwan, we used International Classification of Diseases, Ninth Revision, Clinical Modification (ICD9-CM) diagnosis codes. PC was identified as ICD-9CM procedure code 51.01, and CCS was identified as ICD-9-CM procedure codes 51.2 and 51.21-51.24 [17]. We divided patients who accepted either of the above two operation procedures into PC and CCS patients based on the first operation that they received during their hospital stay. When patients initially underwent PC, they were classified as PC patients. Similarly, patients were classified as CCS patients when they initially underwent CCS. Patients who underwent both $\mathrm{PC}$ and CCS operations during the same hospitalization (i.e., PC as a bridge to CCS surgery) were classified as CCS patients. Only patients of no younger than 18 years who had undergone PC or CCS were included. To analyze procedure causes, ACs with a calculus/stone were defined as patients with ICD-9-CM diagnosis codes 574.0, 574.3, and 574.6; ACs without a calculus/stone were defined as patients with ICD-9-CM diagnosis code 575.0; calculus without ACs referred to patients with ICD-9-CM diagnosis codes 574.1, 574.2, 574.4, 574.5, 574.7, 574.8 , or 574.9 ; other disorders of the gallbladder or biliary tract were designated patients with ICD-9-CM diagnosis codes 575 or 576 excluding diagnosis code 575.0; and malignant neoplasms of digestive organs 
and the peritoneum included patients with ICD-9CM diagnosis codes $150-159$ but omitting diagnosis codes 574,575 , and 576 .

\section{Classification of the low-income population and general population}

The enrolled subjects were divided into two groups based on their socioeconomic status, considered a dichotomous variable: the low-income population (LIP) group and the general population (GP) group, based on the criteria of Taiwan's Social Welfare Act. LIP households were defined as those with monthly incomes of less than the minimum living expense standard of the region of residence. This subgroup was classified into the fifth insured class under the Taiwan NHI database [18]. Family property and the minimum living expense standard were not permitted to exceed $60 \%$ of the average monthly disposable income for the corresponding year and for a given region [19]. The GP included all individuals who were not in the LIP.

\section{Measurement outcomes \\ In-hospital complications}

We examined all-cause, nonfatal in-hospital morbidity rates based on ICD-9-CM codes. Complications were grouped into 9 categories (mechanical wound complications, infections, urinary complications, pulmonary complications, systemic complications, complications arising during procedures, specific complications of the gallbladder/digestive system, respiratory complications, others). As the NHIRD DD dataset includes inpatient data only, complications occurring after hospital discharge were not considered in our analysis.

\section{Mortality}

In-hospital mortality referred to patients who underwent PC or CCS and died during hospitalization. 30day mortality after discharge referred to patients who died within 30-days after their discharges. Total mortality was calculated by including both of the cases died in the hospital and those who died within 30days after their discharges.

\section{Rate of routine discharge}

The NHIRD provides information on patient discharge statuses (1, treated and discharged; 2 , continued to hospital; 3, transferred to outpatient treatment; 4, death; 5 , discharge against medical advice; 6, referral; 7, change in status; 8 , abscond; 9, suicide; 0 , other; and $\mathrm{A}$, discharged while dying). $\mathrm{Pa}$ tients were grouped into the following categories: routine discharge $(1,3)$ and non-routine discharge $(0,2,4-9$, and A).

\section{Readmission due to complications}

Readmission due to complications was designated when readmission occurred due to the diagnosis of a commonly encountered postoperative complication listed in (Table 5 in Appendix) within 3 months after PC or CCS delivery.

\section{Recurrence of Cholecystitis}

Cholecystitis recurrence was designated when readmission occurred due to the diagnosis of cholecystitis after PC or CCS surgery.

\section{Length of hospital stay (LOS)}

The period between admission and discharge was defined as the LOS (measured in days). The LOS was measured as 1 day for patients discharged on the same day that they were admitted to the hospital [20].

\section{Hospital costs}

Hospital costs were calculated by summing all items enumerated in the hospital discharge summary, including operation-associated costs and ward costs. Operation-associated costs included anesthesia and surgery fees as well as costs of medical supplies used during an operation. Surplus costs were classified as ward costs. Costs are expressed in U.S. dollars (USD). In 2007, one USD dollar was equivalent to approximately 32.64 Taiwan dollars [20].

\section{Statistical analysis}

For the analysis, descriptive statistics for comparing baseline characteristics were determined based on the number of cases, percentages, and 95\% confidence intervals (CI) for the estimated rates. Independent t-tests were used to evaluate the significance of differences between two subgroups. Temporal trends were analyzed using joinpoint regression, a statistical method that fits a series of joined straight lines between statistically significant changes in trends (joinpoints). We in turn estimated the change between joinpoints using the National Cancer Institute's Joinpoint Regression Program Version 4.3.1.0 [21, 22]. Long-term trends over the entire time series were designated average annual percentage changes (AAPCs) and were estimated as the weighted average of short-term annual percentage changes with weights equal to the length of the short-term line segment [23]. Binary logistic regression analysis was used, and odds ratios (ORs) were calculated. All statistical analyses were performed 
using the Statistical Package for Social Sciences for Windows (SPSS for Windows Version 19.0).

\section{Results}

From 2003 to 2012, a total of 236,742 patients had undergone PC or CCS. Among them, 11,184 patients (4.72\%) underwent $\mathrm{PC}$, and the remaining 225,558 patients (95.28\%) underwent CCS. The average ages of the patients who had undergone PC and CCS were $70.8 \pm$ 14.6 years and $56.8 \pm 16.2$ years, respectively. The crude rate of PC was 6.09 per 100,000 per year (95\% CI: 4.567.62), and the crude rate of CCS was 124.59 per 100,000 per year (95\% CI: 117.68-131.51).

As shown in Fig. 1, long-term trends (AAPCs) between 2003 and 2012 increased significantly by $18.34 \%$ per year for patients who underwent PC (from 0.69 to 10.59 per 100,000 ) and by $2.82 \%$ per year for patients who underwent CCS (from 107.88 to 132.67 per 100,000$)$. The short-term trends (APCs) for PC and CCS were also significantly different. The age-specific percentages of patients undergoing $\mathrm{PC}$ and CCS are shown in Fig. 2. The proportions of patients who underwent $\mathrm{PC}$ showed a very significant growth trend with age; most patients were 70 years of age or older, with this age group accounting for $61.52 \%$ of all patients. Although the proportion of CCS for each age group also showed a gradual increasing trend with age, the distribution was relatively uniform for each age group (Fig. 2).
The demographic characteristics of the patients undergoing PC and CCS are shown in Table 1. The distributions of PC and CCS varied greatly among the different variables. As shown in Table 2, the patients who underwent PC were associated with higher rates of mortality and readmission due to complications but lower rates of in-hospital complications and routine discharge relative to the patients who underwent CCS. Among the patients who died during hospitalization or within 30 days after CCS, $3103(62.22 \%)$ were male and $1884(37.78 \%)$ were female; on average, the patients were $70.5 \pm 14.7$ years of age, and 3001 patients $(60.18 \%)$ had a CCI score of at least 1 . Correspondingly, for patients who died during hospitalization or within 30 days after PC, $1102(60.32 \%)$ were male, and $725(39.68 \%)$ were female; on average, the patients were $73.3 \pm 14.0$ years of age, and 1117 patients $(61.14 \%)$ had a CCI score of at least 1. As shown in Fig. 3, the AAPCs of total mortality from 2003 to 2012 decreased by $6.78 \%$ per year for PC from $27.12 \%$ to $8.47 \%$ and by $7.33 \%$ per year for CCS from $3.16 \%$ to $1.06 \%$.

Table 3 showed that PC was correlated with a significantly longer LOS and a much higher cost than CCS. The age-specific hospitalization times and hospital costs showed that the mean LOS and costs for the patients who underwent PC were higher than those for the patients who underwent CCS across all age groups (Figs. 4 and 5). Compared to the patients who underwent CCS, a significantly higher percentage of the patients who

Percutaneous Cholecystostomy : 2 Joinpoints versus Cholecystectomy : 2 Joinpoints
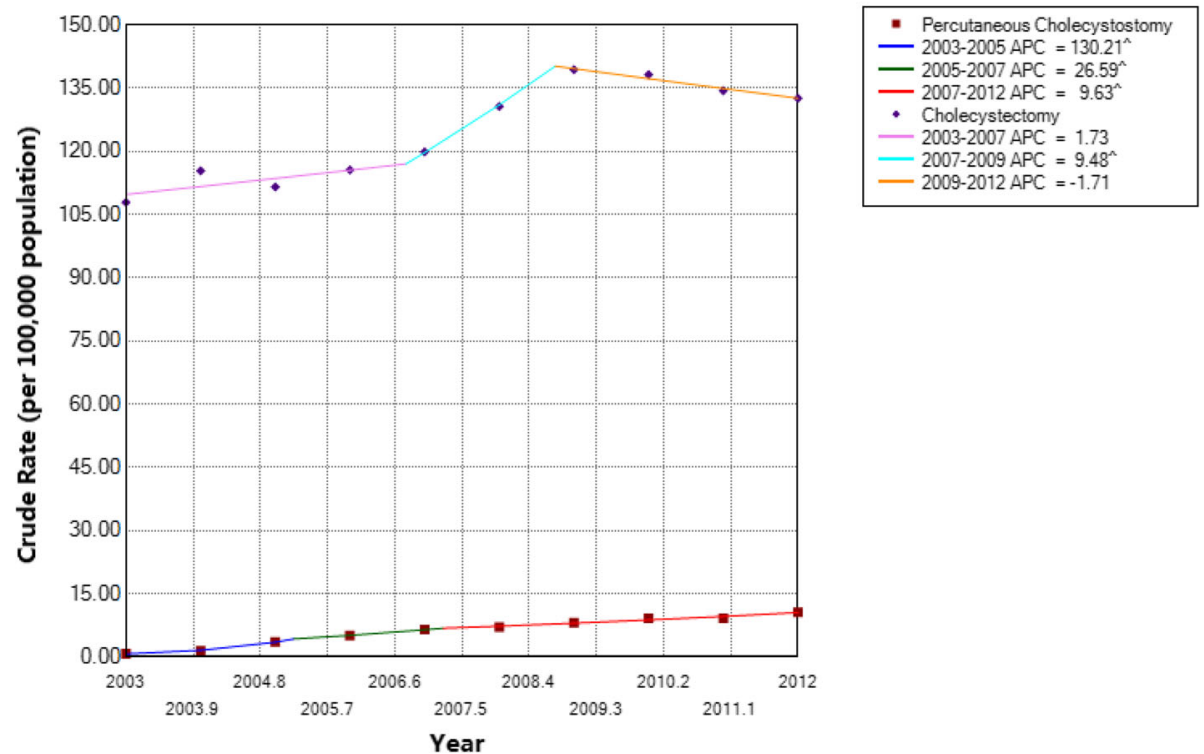

Fig. 1 Comparison of the crude rates for patients who underwent percutaneous cholecystostomy and cholecystectomy in Taiwan from 2003 to 2012 


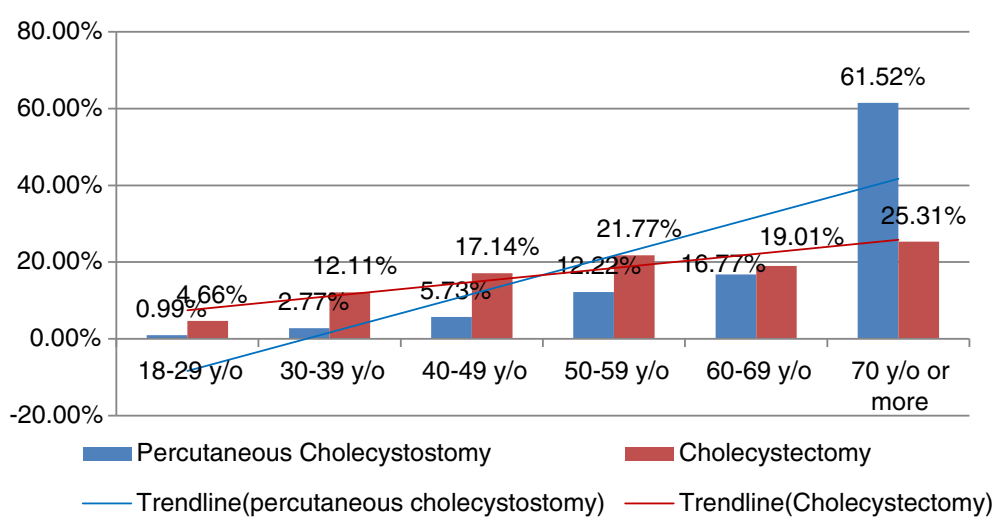

Fig. 2 Age-specific proportions of patients who underwent percutaneous cholecystostomy and cholecystectomy in Taiwan from 2003 to 2012

underwent PC had a LOS period longer than 14 days $(40.15 \%$ vs. $20.63 \%, p<0.001)$ (Fig. 6).

Table 4 shows the relative risk of death among the patients who underwent PC versus the patients who underwent CCS. The in-hospital and 30-day mortality after discharge rates of PC were higher than those of CCS in all subgroups, and the in-hospital and 30-day mortality after discharge rates had similar distributions for each variable.

\section{Discussion}

The management of gallstone disease in the elderly and critically ill is often more challenging because these patients experience a high incidence of cholelithiasis complications [24], and PC has been described as a safe alternative treatment option for AC in elderly or critically ill patients $[1,3,13,17]$. Our findings confirm that most patients who undergo PC were elderly or critically ill. For instance, the proportion of PC patients aged 70 years or older was significantly higher than the proportion of CCS patients in this age group $(61.52 \%$ for PC vs. $25.31 \%$ for CCS, $p<0.001$ ) (Table 1). Moreover, the proportion of patients with a CCI score of 1 or more was higher among the patients who underwent $\mathrm{PC}$ than that among the patients who underwent CCS $(50.88 \%$ for PC vs. $30.16 \%$ for CCS, $p<0.001$ ), and the proportion of patients who underwent $\mathrm{PC}$ with $\mathrm{AC}$ cholelithiasis complications was higher than the proportion of CCS patients $(67.42 \%$ for PC vs. $32.61 \%$ for CCS, $p<$ 0.001) (Table 1).

Temporal trends in the crude rate of patients undergoing PC increased significantly by $18.34 \%$ per year (AAPCs) from 2003 to 2012, although the levels increased by only $2.82 \%$ per year (AAPCs) for CCS over the observed period, and a steady decline of $1.71 \%$ per year was found from 2009 to 2012 (Fig. 1). This result shows that PC operations have gained wide acceptance as a form of AC treatment in Taiwan in recent years. This phenomenon is consistent with trends revealed through some previous studies showing that PC use has gradually increased. Lin et al. [8] reported that the rate of PC use markedly increased from $0.5 \%$ in 2005 to $12.2 \%$ in 2015 and that this procedure has been more commonly applied among the elderly $(p=0.009)$. Duszak Jr. and Behrman [25] reported that annual PC procedures increased by $567 \%$ between 1994 and 2009 . Smith et al. [26] also reported an increased use of PC for the treatment of AC over a 20 -year period at a single institution. The improvement in medical technology and decrease in the mortality levels may be partially attributed to this increased use of PC procedures. Taiwan's aging population may also have affected the increase in PC use, as PC has been established as a treatment option for AC among elderly and critically ill patients [26, 27], and the number of elderly and critically ill patients may increase as the elderly population ages. Meanwhile, the publication of the Tokyo guidelines in 2007 may also have affected this trend; as shown in Fig. 1, there was a downward trend from 2009 to 2012 for patients undergoing CCS, whereas the crude rate of PC showed a steady upward trend from 2003 to 2012.

The controversy over the role of percutaneous gallbladder drainage is based on the opinion expressed by some authors that mortality is far higher after PC than CCS, even for critically ill patients [4, 5, 13]. Winbladh et al. [13] reviewed 53 studies and found that the 30-day and in-hospital mortality rates after PC were high $(15.4 \%)$, whereas the rates for those treated with CCS were low (4.5\%). Aljundi et al. [5] reported a 30 -day mortality rate of $16.7 \%$ for patients after PC. Campanile et al. [28] conducted a survey of the literature and showed that the in-hospital mortality rate for cholecystostomy varied between 4 and 
Table 1 Demographic characteristics of patients who underwent percutaneous cholecystostomy and cholecystectomy in Taiwan from 2003 to 2012

\begin{tabular}{|c|c|c|c|c|c|c|c|}
\hline \multirow[t]{2}{*}{ Variable } & \multicolumn{2}{|c|}{ Total $(n=236,742)$} & \multicolumn{2}{|c|}{ Percutaneous cholecystostomy ( $n=11,184,4.72 \%)$} & \multicolumn{2}{|c|}{ Cholecystectomy ( $n=225,558,95.28 \%)$} & \multirow[t]{2}{*}{$P$-value } \\
\hline & $\mathrm{n}$ & $\%$ & $\mathrm{n}$ & $\%$ & $\mathrm{n}$ & $\%$ & \\
\hline Sex & & & & & & & $<0.001$ \\
\hline Female & 119,108 & $50.31 \%$ & 4570 & $40.86 \%$ & 114,538 & $50.78 \%$ & \\
\hline Male & 117,634 & $49.69 \%$ & 6614 & $59.14 \%$ & 111,020 & $49.22 \%$ & \\
\hline Age stratum & & & & & & & $<0.001$ \\
\hline $18-29$ y/o & 10,628 & $4.49 \%$ & 111 & $0.99 \%$ & 10,517 & $4.66 \%$ & \\
\hline $30-39$ y/o & 27,628 & $11.67 \%$ & 310 & $2.77 \%$ & 27,318 & $12.11 \%$ & \\
\hline $40-49$ y/o & 39,299 & $16.60 \%$ & 641 & $5.73 \%$ & 38,658 & $17.14 \%$ & \\
\hline $50-59$ y/o & 50,474 & $21.32 \%$ & 1367 & $12.22 \%$ & 49,107 & $21.77 \%$ & \\
\hline $60-69$ y/o & 44,744 & $18.90 \%$ & 1875 & $16.77 \%$ & 42,869 & $19.01 \%$ & \\
\hline 70 y/o or more & 63,969 & $27.02 \%$ & 6880 & $61.52 \%$ & 57,089 & $25.31 \%$ & \\
\hline Cause of procedure & & & & & & & $<0.001$ \\
\hline AC with a $C / S$ & 68,507 & $28.94 \%$ & 4116 & $36.80 \%$ & 64,391 & $28.55 \%$ & \\
\hline$A C$ without a $C / S$ & 12,597 & $5.32 \%$ & 3424 & $30.62 \%$ & 9173 & $4.07 \%$ & \\
\hline Calculus without AC & 116,285 & $49.12 \%$ & 1244 & $11.12 \%$ & 115,041 & $51.00 \%$ & \\
\hline ODGBT & 15,033 & $6.35 \%$ & 1381 & $12.35 \%$ & 13,652 & $6.05 \%$ & \\
\hline MNDOP & 18,747 & $7.92 \%$ & 354 & $3.17 \%$ & 18,393 & $8.15 \%$ & \\
\hline Others & 5573 & $2.35 \%$ & 665 & $5.95 \%$ & 4908 & $2.18 \%$ & \\
\hline CCl score & & & & & & & $<0.001$ \\
\hline 0 & 163,028 & $68.86 \%$ & 5494 & $49.12 \%$ & 157,534 & $69.84 \%$ & \\
\hline 1 & 31,985 & $13.51 \%$ & 2828 & $25.29 \%$ & 29,157 & $12.93 \%$ & \\
\hline 2 & 23,314 & $9.85 \%$ & 1426 & $12.75 \%$ & 21,888 & $9.70 \%$ & \\
\hline$\geq 3$ & 18,415 & $7.78 \%$ & 1436 & $12.84 \%$ & 16,979 & $7.53 \%$ & \\
\hline Socioeconomic Status & & & & & & & 0.007 \\
\hline GP & 234,136 & $98.90 \%$ & 11,032 & $98.64 \%$ & 223,104 & $98.91 \%$ & \\
\hline LIP & 2606 & $1.10 \%$ & 152 & $1.36 \%$ & 2454 & $1.09 \%$ & \\
\hline Hospital level & & & & & & & $<0.001$ \\
\hline Medical center & 112,537 & $47.54 \%$ & 6265 & $56.02 \%$ & 106,272 & $47.12 \%$ & \\
\hline Regional hospital & 105,701 & $44.65 \%$ & 4627 & $41.37 \%$ & 101,074 & $44.81 \%$ & \\
\hline District hospital & 18,504 & $7.82 \%$ & 292 & $2.61 \%$ & 18,212 & $8.07 \%$ & \\
\hline
\end{tabular}

$A C$ acute cholecystitis, $C / S$ calculus/stone, ODGBT other disorders of gallbladder or biliary tract, MNDOP malignant neoplasm of digestive organs and the peritoneum, CCI Charlson Comorbidity Index, LIP low-income population, GP general population

$50 \%$ and that the associated morbidity rate varied between 8.2 and $62 \%$. It is unclear whether this difference in mortality is attributable to the fact that patients who underwent PC are at a higher risk of mortality than patients who underwent CCS [13]. In the present study, we also found that the in-hospital and 30-day mortality after discharge rates were significantly higher among patients who underwent PC than among patients who underwent CCS (Table 2). This result is consistent with the rates reported in some existing studies, as mentioned above. However, because the general conditions are far worse in the average PC patient than in the average CCS patient, we cannot conclude that mortality is higher for PC than for CCS from simple comparisons. Instead, indepth subset analyses must be conducted to justify this finding. Therefore, we compared the mortality rates between patients who underwent PC and CCS stratified by sex, age, cause of procedure and $\mathrm{CCI}$ score group.

The results are shown in Table 4. The mortality rates were far higher among patients who underwent PC than among patients who underwent CCS in all subgroups, which increased from a minimum of 1.45 -fold to a maximum of 34.22-fold. Based on the subset analyses, we conclude that PC is not as safe 
Table 2 Characteristics of in-hospital complications, in-hospital mortality rates, routine discharge rates, readmissions for complications, and cholecystitis recurrence rates

\begin{tabular}{|c|c|c|c|c|}
\hline \multirow[t]{2}{*}{ Variables } & \multirow[t]{2}{*}{ All $(N, \%)$} & \multicolumn{2}{|l|}{ Procedure type $(\mathrm{N}, \%)$} & \multirow[t]{2}{*}{$P$-value } \\
\hline & & Percutaneous cholecystostomy & Cholecystectomy & \\
\hline Total mortality ${ }^{a}$ & $6814(2.88 \%)$ & $1827(16.34 \%)$ & $4987(2.21 \%)$ & $<0.001$ \\
\hline In-hospital mortality & $4936(2.08 \%)$ & $1334(11.93 \%)$ & $3602(1.60 \%)$ & $<0.001$ \\
\hline 30-day mortality after discharge & $1878(0.80 \%)$ & $493(4.41 \%)$ & $1385(0.61 \%)$ & $<0.001$ \\
\hline In-hospital complications ${ }^{b}$ & 9320 (3.94\%) & $231(2.07 \%)$ & 9089 (4.03\%) & $<0.001$ \\
\hline Specific gallbladder/digestive system complications & $4758(2.01 \%)$ & $84(0.75 \%)$ & $4674(2.07 \%)$ & $<0.001$ \\
\hline Infections & $2904(1.23 \%)$ & $54(0.48 \%)$ & $2850(1.26 \%)$ & $<0.001$ \\
\hline Mechanical wound complications & $1358(0.57 \%)$ & $38(0.34 \%)$ & $1320(0.59 \%)$ & 0.001 \\
\hline Complications during procedures & $908(0.38 \%)$ & $26(0.23 \%)$ & $882(0.39 \%)$ & 0.008 \\
\hline Pulmonary complications & $363(0.15 \%)$ & $53(0.47 \%)$ & $310(0.14 \%)$ & $<0.001$ \\
\hline Systemic complications & $160(0.07 \%)$ & $4(0.04 \%)$ & $156(0.07 \%)$ & 0.185 \\
\hline Respiratory & $82(0.03 \%)$ & $8(0.07 \%)$ & $74(0.03 \%)$ & 0.032 \\
\hline Urinary complications & $22(0.01 \%)$ & $0(0.00 \%)$ & $22(0.01 \%)$ & 0.296 \\
\hline Other & $42(0.02 \%)$ & $2(0.02 \%)$ & $40(0.02 \%)$ & 0.991 \\
\hline Rates of routine discharge & $229,336(96.87 \%)$ & $9092(81.29 \%)$ & $220,244(97.64 \%)$ & $<0.001$ \\
\hline Treatment and discharge & $13,208(5.58 \%)$ & $739(6.61 \%)$ & $12,469(5.53 \%)$ & $<0.001$ \\
\hline Transferred to outpatient treatment & $216,128(91.29 \%)$ & 8353 (74.69\%) & $207,775(92.12 \%)$ & $<0.001$ \\
\hline Readmission due to complications & $3523(1.49 \%)$ & $386(3.45 \%)$ & $3137(1.39 \%)$ & $<0.001$ \\
\hline Recurrence of cholecystitis & - & $2856(25.54 \%)$ & - & - \\
\hline Cholecystectomy delivered & - & $2419(21.63 \%)$ & - & - \\
\hline Elective cholecystectomy & - & 1652 (14.78\%) & - & - \\
\hline
\end{tabular}

${ }^{a}$ Total mortality was calculated by including both of the cases died in hospital and those who died within 30-days after their discharges

${ }^{\mathrm{b}}$ Two or more complications occurred for the same patient; thus, the total number of patients with complications was less than the sum of the number of patients with each independent complication

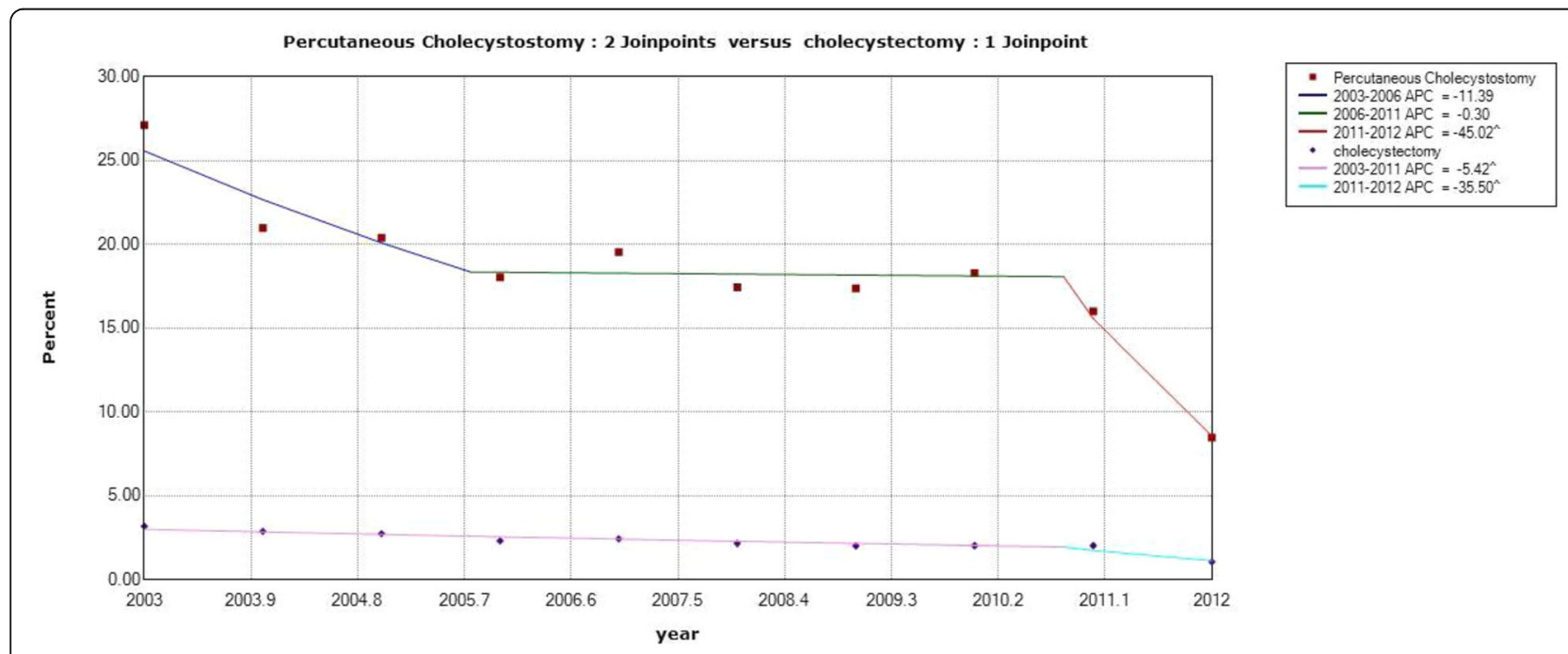

Fig. 3 Comparison of mortality rates for patients who underwent percutaneous cholecystostomy and cholecystectomy in Taiwan from 2003 to 2012 
Table 3 Medical utilization for patients who underwent percutaneous cholecystostomy and cholecystectomy in Taiwan from 2003 to 2012

\begin{tabular}{llll}
\hline Procedure type & $\begin{array}{l}\text { Summed cases } \\
\text { 2003-2012(\%) }\end{array}$ & $\begin{array}{l}\text { LOS (days) } \\
\text { Mean } \pm \text { SE }\end{array}$ & $\begin{array}{l}\text { Cost (USD) } \\
\text { Mean } \pm \text { SE }\end{array}$ \\
\hline Cholecystectomy & $225,558(95.28 \%)$ & $9.51 \pm$ & $2836.86 \pm$ \\
Percutaneous & $11,184(4.72 \%)$ & $17.20 \pm$ & 8.59 \\
Cholecystostomy & & 1.52 & $4106.71 \pm$ \\
P-value & & $<0.001$ & $<0.001$ \\
\hline
\end{tabular}

as the Tokyo guidelines suggested in moderate-grade cholecystitis cases and actually its mortality rate is higher than that of CCS, even in the worst scenario (elderly patients with $\mathrm{AC}$ and a CCI score of 3 or more) and that the relative risk of death for $\mathrm{PC}$ is 1.45 -fold higher than that for CCS. We also found that the gap of the in-hospital and 30-day mortality after discharge rates narrowed as the patients aged and with the seriousness of the diseases. In other words, the relative risk of death is higher in less compromised patients but lower in the most serious patients. This important aspect means that PC should be limited only to elderly and sicker patients because in all other patients, the risk seems to be excessive. Additionally, we found that most patients with PC or CCS who died in the hospital or within 30 days after an operation were 70 years of age or older $(73.3 \pm 14.0$ years old after PC and $70.5 \pm$ 14.7 years old after CCS). Moreover, a large number of these patients generated a CCI score of 1 or more (61.14\% after PC and $60.18 \%$ after CCS), which indicates that being elderly and critically ill may cause patients to be more likely to die during hospitalization or within 30 days after discharge for both types of operations.
As shown in Fig. 3, long-term trends of overall mortality from 2003 to 2012 for both operations declined significantly. For PC, the overall mortality rate decreased from $27.12 \%$ in 2003 to $8.47 \%$ in 2012 . These improved mortality rates for recent years align with the results of some previous studies. Winbladh et al. [13] summarized 52 papers and stated that the total mortality rate listed in earlier papers was $22.1 \%$ (20 papers published before 1996), while this rate was reported at $13.3 \%$ in more recent studies (32 papers published after 1995), revealing a significantly decreasing trend. Smith et al. [26] reported that the 30-day mortality rate decreased from 36 to $12 \%$ among patients undergoing PC from 1998 to 2009, and these authors suggested that patient selection procedures may play a major role in these reduced mortality rates. In addition, we found that the proportion of males was significantly higher than that of females among patients who died during hospitalization for both operation types $(60.32 \%$ were male for PC, $62.22 \%$ were male for CCS, respectively), although the total number of patients was closely balanced between males and females (50.31\% for females vs. $49.69 \%$ for males, $p<0.001$ ), indicating that males may be more vulnerable than females.

According to our study, PC was associated with a lower rate of in-hospital complications than CCS $(2.07 \%$ vs. $4.03 \%, p<0.001)$. However, of the $36.41 \%$ of patients treated with PC who underwent subsequent CCS procedures, $14.78 \%$ of them underwent elective CCS, and $21.63 \%$ of patients developed recurrent cholecystitis. Winbladh et al. [13] also reported that more than $40 \%$ of all patients eventually undergo CCS surgery, which is consistent with our results. In addition, compared to CCS cases, PC cases were found to be associated with a lower rate of

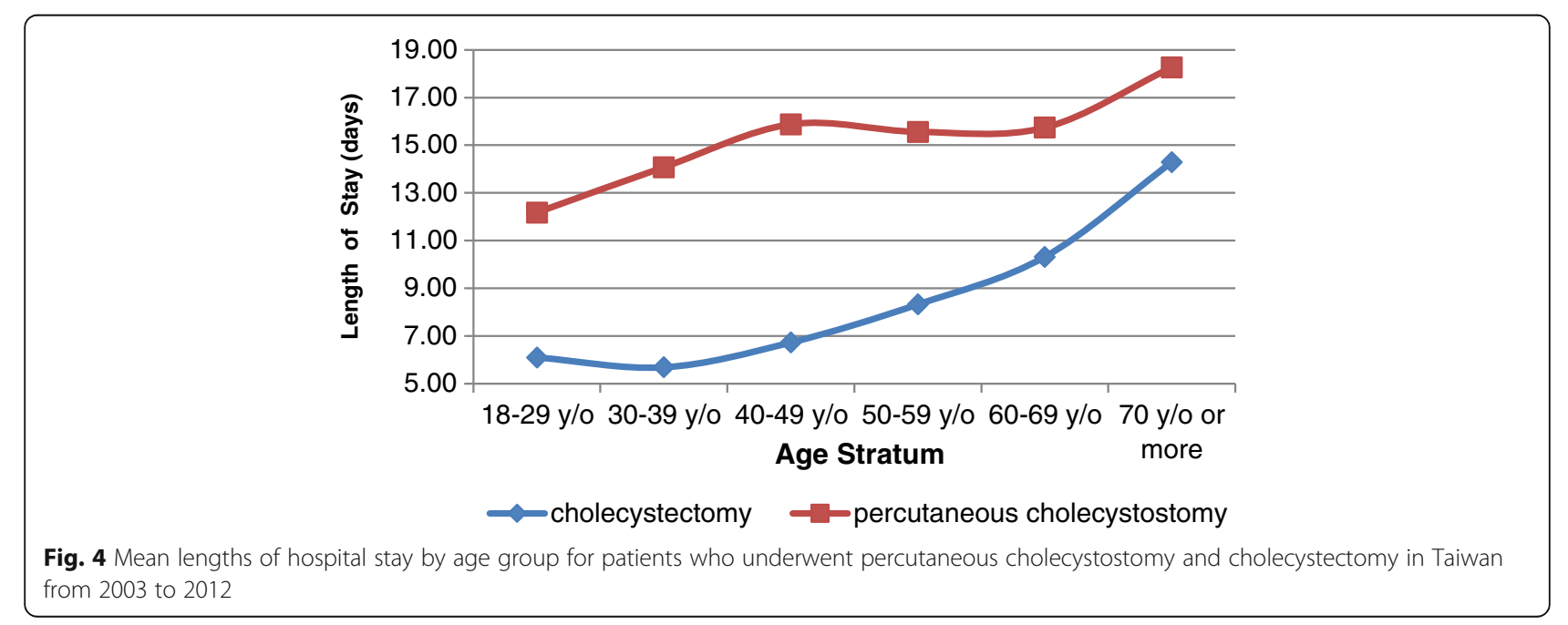




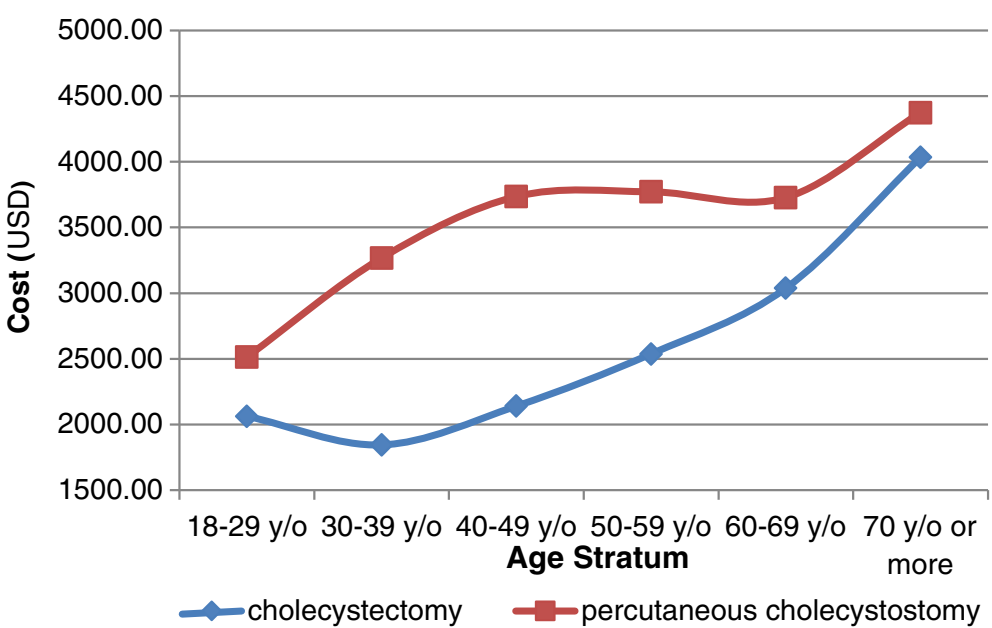

Fig. 5 Average hospital costs by age group for patients who underwent percutaneous cholecystostomy and cholecystectomy in Taiwan from 2003 to 2011

routine discharge $(81.29 \%$ after $\mathrm{PC}$ and $97.64 \%$ after CCS), reflecting the poor prognosis of patients with PC relative to that of patients with CCS (Table 2). The costs and LOS values for patients undergoing PC were significantly higher than those for patients undergoing CCS. If we do not consider the age difference for the overall subpopulation, as shown in Figs. 4 and 5, the costs and LOS values for the PC patients are higher than those for the CCS patients for each age stratum. Anderson et al. [17] also found higher mean LOS values and costs for patients undergoing PC (for both acute calculus and acalculus cholecystitis) than for patients receiving CCS even after adjusting for age, race, sex, CCI, teaching hospital status, and year variables.

The present study has some limitations. First, we could not obtain complete details on the general conditions for all patients due to the limitations of the data, which made it difficult to accurately determine the illness severity and thus made it difficult to group the patients in homogeneous PC and CCS groups. However, to the best of our knowledge, the results concerning the relative risk of mortality are stratified by the patients' general conditions, to the greatest extent possible, including sex, age, cause of procedure and CCI score groups. Second, some patients who underwent PC could not have tolerated any surgery, but we cannot identify these patients, which is an important selection bias in our study. Third, similar to in other administrative and database-based studies, detailed clinical data and examination information could not be obtained in this study. As we could not review the individual medical records to ensure that the records were coded precisely, deviations may exist between the codes and the actual

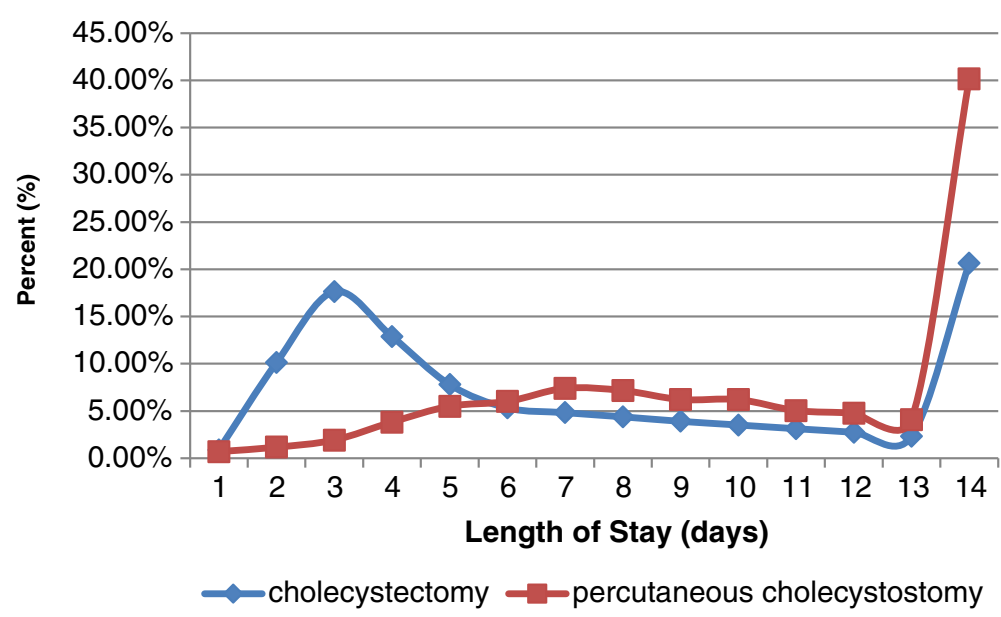

Fig. 6 Frequency distributions of hospital length of stay for patients who underwent percutaneous cholecystostomy and cholecystectomy 
Table 4 Related factors (represented by their odds ratio) of death among patients underwent percutaneous cholecystostomy versus patients underwent cholecystectomy

\begin{tabular}{|c|c|c|c|}
\hline \multirow[t]{2}{*}{ Stratified variables } & In-hospital mortality & 30-day mortality after discharge & Total mortality $^{a}$ \\
\hline & OR $(95 \% \mathrm{Cl})$ & OR $(95 \% \mathrm{Cl})$ & OR $(95 \% \mathrm{Cl})$ \\
\hline Total & $8.35(7.81,8.92) * * *$ & $7.31(6.61,8.10) * * *$ & $8.64(8.15,9.15) * * *$ \\
\hline \multicolumn{4}{|l|}{ Sex } \\
\hline Female & $11.45(10.31,12.72) * * *$ & $8.87(7.54,10.44) * * *$ & $11.28(10.29,12.36) * * *$ \\
\hline Male & $6.52(5.99,7.09) * * *$ & $6.18(5.43,7.04) * * *$ & $6.95(6.46,7.49) * * *$ \\
\hline \multicolumn{4}{|l|}{ Age stratum } \\
\hline $18-29$ y/o & $12.46(5.22,29.75) * * *$ & $9.63(2.22,41.71)^{* *}$ & $13.31(6.21,28.53) * * *$ \\
\hline $30-39$ y/o & $34.22(22.76,51.44) * * *$ & $16.23(8.20,32.11) * * *$ & $30.57(21.38,43.73) * * *$ \\
\hline $40-49$ y/o & $20.07(15.15,26.59) * * *$ & $15.34(9.84,23.93) * * *$ & $20.72(16.22,26.47)^{* * *}$ \\
\hline $50-59$ y/o & $12.88(10.39,15.96) * * *$ & $9.37(6.77,12.96) * * *$ & $12.42(10.33,14.94) * * *$ \\
\hline $60-69$ y/o & $8.34(7.01,9.91)^{* * *}$ & $6.62(5.16,8.50) * * *$ & $8.25(7.12,9.55) * * *$ \\
\hline $70 \mathrm{y} / \mathrm{o}$ or more & $3.67(3.38,3.98) * * *$ & $3.65(3.21,4.14) * * *$ & $3.89(3.62,4.18) * * *$ \\
\hline \multicolumn{4}{|l|}{ Cause of procedures } \\
\hline AC with a $C / S$ & $4.43(3.80,5.17) * * *$ & $5.03(4.07,6.21)^{* * *}$ & $4.77(4.20,5.42) * * *$ \\
\hline AC without a $C / S$ & $2.62(2.26,3.03) * * *$ & $3.59(2.84,4.54) * * *$ & $3.02(2.65,3.43) * * *$ \\
\hline Calculus without $A C$ & $13.25(10.89,16.13) * * *$ & $7.30(5.20,10.25)^{* * *}$ & $11.87(9.97,14.13)^{* * *}$ \\
\hline ODGBT & $12.08(10.18,14.32) * * *$ & $10.87(8.44,14.00) * * *$ & $13.64(11.74,15.84) * * *$ \\
\hline MNDOP & $10.51(8.24,13.42) * * *$ & $6.97(4.87,9.98) * * *$ & $11.19(8.95,14.01)^{* * *}$ \\
\hline Others & $4.61(3.83,5.56) * * *$ & $3.44(2.36,5.02) * * *$ & $5.29(4.42,6.33) * * *$ \\
\hline \multicolumn{4}{|l|}{ CCl score } \\
\hline 0 & $11.39(10.29,12.62) * * *$ & $9.70(8.17,11.51) * * *$ & $11.62(10.62,12.72) * * *$ \\
\hline 1 & $5.19(4.42,6.08)^{* * *}$ & $3.88(3.02,5.00) * * *$ & $5.01(4.36,5.75) * * *$ \\
\hline 2 & $6.52(5.56,7.64) * * *$ & $5.96(4.75,7.48) * * *$ & $7.07(6.16,8.12) * * *$ \\
\hline$\geq 3$ & $4.79(4.16,5.52) * * *$ & $4.52(3.73,5.49) * * *$ & $5.42(4.79,6.14) * * *$ \\
\hline \multicolumn{4}{|l|}{ Other } \\
\hline 70 y/o or more \& $A C \& C C l \geq 3$ & $1.45(1.01,2.09) *$ & $2.48(1.51,4.06) * * *$ & $1.72(1.07,2.77) * * *$ \\
\hline
\end{tabular}

severity of disease conditions. Finally, data on postoperative conditions were also not included. Even so, this national population-based claims database can be recognized as reliable because it has been adopted in many research fields and numerous high-impact publications.

\section{Conclusions}

In conclusion, the present study found that patients after PC had some poor prognoses compared with patients after CCS, such as a higher rate of mortality and cholecystitis recurrence, but a lower rate of routine discharge. Furthermore, the subset analyses demonstrated that the mortality rates were far higher in the patients who underwent PC than in the patients who underwent CCS in all subgroups, even in the worst scenario (elderly patients with $\mathrm{AC}$ and a CCI score of 3 or more), but the gap of the mortality rates between PC group and CCS group narrowed as the patients aged and with the seriousness of the diseases increased. The Tokyo guidelines considered the use of PC mandatory for "severe" cases and strongly suggested that this procedure be used even in most moderate-grade cholecystitis cases; however, the present study determined that the role of $\mathrm{PC}$ in the Tokyo guidelines may be overstated. It is not as safe as the Tokyo guidelines suggested in moderate-grade cholecystitis cases, and it should be limited only to elderly and sicker patients. But still, as medical technology has improved, the mortality rates of PC have decreased, and the aging population has increased, we suggest strengthening and paying more attention to the use of PC technology in elderly and seriously ill patients. 


\section{Appendix}

Table 5 ICD-9 codes for postoperative in-hospital complications

\begin{tabular}{ll}
\hline Complications & ICD-9 Codes \\
\hline Mechanical wound complications & $998.12,998.13,998.3,998.6$, and 998.83 \\
Infections & $998.5,998.51$, and 998.59 \\
Urinary complications & 997.5 \\
Pulmonary complications & $512.1,518.4,518.5$, and 997.3 \\
Systemic complications & 998.0 and 998.89 \\
Complications during procedure & $998.11,998.2$, and 998.4 \\
Specific complications of the gallbladder/digestive system & $997.4,576.0,998.6,576.4,575.5,51.36,51.37,51.39,51.71,51.72$, and 51.79 \\
Respiratory & $997.3,997.31,997.39$ \\
Other & $998.4,998.7,998.8,998.89,998.9$ \\
\hline
\end{tabular}

\section{Abbreviations}

AAPC: Average annual percentage change; AC: Acute cholecystitis; APC: Short-term trend; CCl: Charlson Comorbidity Index; CCS: Cholecystectomy; Cl: Confidence interval; GP: General population; LIP: Low-income population; LOS: Length of hospital stays; NHI: National Health Insurance; NHIRD: National Health Insurance Research Database; PC: Percutaneous cholecystostomy

\section{Acknowledgments}

This study is based in part on data from the National Health Insurance Research Database provided by the National Health Insurance Administration and Ministry of Health and Welfare and was managed by the National Health Research Institutes.

\section{Funding}

This study was partially supported by the Ministry of Science and Technology (MOST 104-2218-E-155-004 and MOST-105-2221-E-155-041-MY3), and the research project of Xiamen overseas students (XRS201631401).

\section{Availability of data and materials}

The data that support the findings of this study are available from the Taiwan National Health Research Institutes, but restrictions apply to the availability of these data, which were used under license for the current study and are not publicly available. However, the data are available from the authors upon reasonable request and with permission of the Taiwan National Health Research Institutes.

\section{Authors' contributions}

The study was designed by PL, CLC, and NPY; data were gathered and analyzed by NTC, NPY, and KRL; the initial draft of the manuscript was written by KRL, PL and KBL; and the accuracy of the data and analyses was ensured by CLC and NTC. All the authors helped prepare the manuscript and approved of the final version. All the authors read and approved the final manuscript. PL, CLC, NTC and KRL contributed equally to this work.

\section{Ethics approval and consent to participate}

This study was approved by the research ethics committee of Taoyuan General Hospital (Approval Number: TYGH103015), which has been certified by the Ministry of Health \& Welfare of Taiwan, and the research protocol was required to be reviewed by the National Health Research Institutes (Agreement Number: NHIRD-104-081).

\section{Consent for publication}

Not applicable.

\section{Competing interests}

The authors declare that they have no competing interests.

\section{Publisher's Note}

Springer Nature remains neutral with regard to jurisdictional claims in published maps and institutional affiliations.

\section{Author details}

${ }^{1}$ School of Economics and Management, Xiamen University of Technology, Xiamen 361024, China. ${ }^{2}$ Department of Information Management, Yuan Ze University, Taoyuan 32003, Taiwan. ${ }^{3}$ Department of Surgery, Keelung Hospital, Ministry of Health and Welfare, Keelung 20147, Taiwan. ${ }^{4}$ Institute of Public Health, National Yang-Ming University, Taipei 11221, Taiwan. ${ }^{5}$ School of Nursing, College of Medicine, National Taiwan University, Taipei 10051, Taiwan. ${ }^{6}$ Department of Computer Science and Engineering, Yuan Ze University, Taoyuan 32003, Taiwan. ${ }^{7}$ School of Computer \& Information Engineering, Xiamen University of Technology, Xiamen 361024, China. ${ }^{8}$ Innovation Center for Big Data and Digital Convergence, Yuan Ze University, Taoyuan 32003, Taiwan.

Received: 26 June 2017 Accepted: 24 November 2017

Published online: 07 December 2017

\section{References}

1. Abi-Haidar Y, Sanchez V, Williams SA, Itani KM. Revisiting percutaneous cholecystostomy for acute cholecystitis based on a 10-year experience. Arch Surg. 2012;147:416-22.

2. Campanile FC, Carrara A, Motter M, Ansaloni L, Agresta F. Laparoscopy and acute cholecystitis: the evidence. In: Agresta F, Campanile F, Vettoretto $N$, editors. Laparoscopic cholecystectomy. Cham: Springer; 2014. p. 59-72

3. Byrne MF, Suhocki $P$, Mitchell RM, Pappas TN, Stiffler $H L$, Jowell PS, et al. Percutaneous cholecystostomy in patients with acute cholecystitis: experience of 45 patients at a US referral center. J Am Coll Surg. 2003; 197:206-11.

4. Teoh WM, Cade RJ, Banting SW, Mackay S, Hassen AS. Percutaneous cholecystostomy in the management of acute cholecystitis. ANZ J Surg. 2005;75:396-8.

5. Aljundi W, Cannon T, Antakia R, Anoop U, Balamurugan R, Everitt N, et al. Percutaneous cholecystostomy as an alternative to cholecystectomy in high risk patients with biliary sepsis: a district general hospital experience. Ann R Coll Surg Engl. 2012;94:99-101.

6. Shirai Y, Tsukada K, Kawaguchi H, Ohtani T, Muto T, Hatakeyama K. Percutaneous transhepatic cholecystostomy for acute acalculous cholecystitis. Br J Surg. 1993;80:1440-2.

7. Yeo CS, Tay WW, Low JK, Woon WW, Punamiya SJ, Shelat VG. Outcomes of percutaneous cholecystostomy and predictors of eventual cholecystectomy. J Hepatobiliary Pancreat Sci. 2016;23:65-73.

8. Lin WC, Chang CW, Chu CH. Percutaneous cholecystostomy for acute cholecystitis in high-risk elderly patients. Kaohsiung J Med Sci. 2016:32: $518-25$. 
9. Wada K, Takada T, Kawarada Y, Nimura Y, Miura F, Yoshida M, et al. Diagnostic criteria and severity assessment of acute cholangitis: Tokyo guidelines. J Hepato-Biliary-Pancreat Surg. 2007;14:52-8.

10. Yamashita Y, Takada T, Strasberg SM, Pitt HA, Gouma DJ, Garden OJ, et al. TG13 surgical management of acute cholecystitis. J Hepatobiliary Pancreat Sci. 2013;20:89-96.

11. Pang KW, Tan CH, Loh S, Chang KY, lyer SG, Madhavan K, et al. Outcomes of percutaneous cholecystostomy for acute cholecystitis. World J Surg. 2016;40: 2735-44.

12. Kortram K, van Ramshorst B, Bollen TL, Besselink MG, Gouma DJ, Karsten T, et al. Acute cholecystitis in high risk surgical patients: percutaneous cholecystostomy versus laparoscopic cholecystectomy (CHOCOLATE trial): study protocol for a randomized controlled trial. Trials. 2012;13:7.

13. Winbladh A, Gullstrand P, Svanvik J, Sandström P. Systematic review of cholecystostomy as a treatment option in acute cholecystitis. HPB (Oxford). 2009;11:183-93.

14. Campanile FC, Pisano M, Coccolini F, Catena F, Agresta F, Ansaloni L. Acute cholecystitis: WSES position statement. World J Emerg Surg. 2014;9:1-6.

15. Cull JD, Velasco JM, Czubak A, Rice D, Brown EC. Management of acute cholecystitis: prevalence of percutaneous cholecystostomy and delayed cholecystectomy in the elderly. J Gastrointest Surg. 2014;18:328-33.

16. Huang J, Chang CH, Wang JL, Kuo HK, Lin JW, Shau WY, et al. Nationwide epidemiological study of severe gallstone disease in Taiwan. BMC Gastroenterol. 2009;9:63.

17. Anderson JE, Chang DC, Talamini MA. A nationwide examination of outcomes of percutaneous cholecystostomy compared with cholecystectomy for acute cholecystitis, 1998-2010. Surg Endosc. 2013;27: 3406-11.

18. Emil S, Mikhail P, Laberge JM, Flageole H, Nguyen LT, Shaw KS, et al. Clinical versus sonographic evaluation of acute appendicitis in children: a comparison of patient characteristics and outcomes. J Pediatr Surg. 2001;36:780-3.

19. Ministry of Health and Welfare. Taiwan Social Assistance Act. 2015 http://law.moj.gov.tw/LawClass/LawAll.aspx?PCode=D0050078. Accessed 5 Feb 2015.

20. Lin KB, Lai KR, Yang NP, Chan CL, Liu YH, Pan RH, et al. Epidemiology and socioeconomic features of appendicitis in Taiwan: a 12-year populationbased study. World J Emerg Surg. 2015;10:42.

21. Joinpoint Regression Program. Version 4.3.1.0-April, 2016. Rockville: statistical methodology and applications branch, surveillance research program, National Cancer Institute; 2016.

22. National Cancer Institute. Version 4.3.1.0 - April 2016, joinpoint regression program online help system version 4.3.1.0. Rockville: surveillance research program, statistical methodology and applications branch; 2016.

23. Clegg LX, Hankey BF, Tiwari R, Feuer EJ, Edwards BK. Estimating average annual per cent change in trend analysis. Stat Med. 2009;28:3670-82.

24. Brunt LM, Quasebarth MA, Dunnegan DL, Soper NJ. Outcomes analysis of laparoscopic cholecystectomy in the extremely elderly. Surg Endosc. 2001; 15:700-5.

25. Duszak R Jr, Behrman SW. National trends in percutaneous cholecystostomy between 1994 and 2009: perspectives from Medicare provider claims. J Am Coll Radiol. 2012;9:474-9.

26. Smith TJ, Manske JG, Mathiason MA, Kallies KJ, Kothari SN. Changing trends and outcomes in the use of percutaneous cholecystostomy tubes for acute cholecystitis. Ann Surg. 2013;257:1112-5.

27. Cherng N, Witkowski ET, Sneider EB, Wiseman JT, Lewis J, Litwin DEM, et al. Use of cholecystostomy tubes in the management of patients with primary diagnosis of acute cholecystitis. J Am Coll Surg. 2012;214:196-201.

28. Campanile FC, Giannotti D, Agresta F, Vettoretto N, Rao I. Acute calculous cholecystitis. In: Agresta F, Campanile F, Anania G, Bergamini C, editors. Emergency laparoscopy. Cham: Springer; 2016. p. 7-25.

\section{Submit your next manuscript to BioMed Central and we will help you at every step:}

- We accept pre-submission inquiries

- Our selector tool helps you to find the most relevant journal

- We provide round the clock customer support

- Convenient online submission

- Thorough peer review

- Inclusion in PubMed and all major indexing services

- Maximum visibility for your research

Submit your manuscript at www.biomedcentral.com/submit
C Biomed Central 